The volume as a whole suffers from a lack of unity, even greater than that usually associated with treatises of this kind. This is due to the desire of the author to cater to the elementary as well as to the advanced student, and to his prejudice in favor of algebraic analysis. On the other hand, the author has managed to include and touch upon many different mathematical notions and has laid out before the prospective student of mathematics an adequate array of interesting directions for further edification and investigation, which, after all, might be considered a justification of a set of Lessons in Analysis.

T. H. Hildebrandt

Die Grundlagen der Geometrie, ihre Bedeutung für Philosophie, Mathematik, Physik und Technik. By Hugo Dingler. Stuttgart, Ferdinand Enke, 1933. viii $+76 \mathrm{pp}$.

The author proposes a treatment of the foundations of geometry of a radically new kind, starting, not from a set of axioms whose consequences are to be derived, but from a description and analysis of the experimental process of measuring extended bodies. On this basis he proves that the geometry of physical space is euclidean. "Alle die vielen von Einstein und seiner Schule ohne Überlegung und ohne Erröten vorgebrachten Behauptungen über die Geometrie sind damit für jeden, der noch konsequent und umfassend denken kann, inhaltslos und unmöglich geworden."

The principal error seems to lie in the definition of the concept of a solid body. A body is to be called a solid body if it has the property that, if it is translated along any straight line $g$ and a plane through $g$, then it is translated at the same time along every plane which passes through $g$ and along every parallel to $g$ which lies in one of these planes through $g$ and in or on the body. Assuming the existence of bodies which are solid in this sense, the author is able to prove the euclidean parallel postulate!

\title{
Alonzo Church
}

Algebraic Functions. By Gilbert Ames Bliss. American Mathematical Society Colloquium Publications, Volume 16. New York, 1933. vi+218 pp.

This book, immediately striking for its conciseness, is one of the most remarkable works ever produced on the subject of algebraic functions and their integrals.

The distinguishing feature of the book is its third chapter, on rational functions, which gives an extremely brief and clear account of the theory of divisors. Here the integrands of the three elementary types of abelian integrals are set up by the arithmetic methods of Dedekind and Weber. The arithmetic treatment is definitely simpler and more elegant than the potential-theoretic method of Riemann, or the geometric method of Brill and Noether which is based on the reduction of the singularities of algebraic curves. The theory of divisors, hitherto available chiefly in the ponderous classic treatise of Hensel and Landsberg, is presented by Bliss in hardly more than thirty pages.

A very readable account is given of the topology of Riemann surfaces and of the general properties of abelian integrals. Abel's theorem is presented, with 